\title{
Boundary conditions: Learning to live in a finite world
}

\author{
Peter Timmerman
}

Faculty of Environmental Studies, York University, Canada.

\author{
"Feeling the world as a limited whole -- that is the mystical." \\ --Ludwig Wittgenstein, Tractatus Logico-Philosophicus. \\ "To trace back modern world alienation, its twofold flight \\ from the earth into the universe, and from the world into the self." \\ -- Hannah Arendt, The Human Condition.
}

\section{INTRODUCTION}

It isn't the burgeoning global human population that is the main threat to planetary sustainability, but rather the burgeoning expectations of a global human population rapidly committing itself in ever-increasing waves to the current Western "mindset". This mindset, based on, or at least crystallized by modern economics over the last 200 years, generates a world in which economic actors operate as if each individual were an infinitely desiring self, devoted to expressing itself and its need for "freedom" in a society driven by a dynamic of constant progress, and thereby requiring an infinite bounty of resources on an infinite planet to meet his or her infinite desires. These exploding, fantastic infinities -- the personal and the planetary -- need, reflect, and reinforce each other.

However, we now find ourselves confronted by a new boundary or "frame" within which we find ourselves, a frame that presents us with a fundamental challenge: the challenge of living in an interdependent, "no growth", and finite world. The unexpected arrival of the first powerful symbol of the finite in modern times -the Earth seen from space as a bounded sphere - and the grimness of subsequent scientific warnings about our increasing encroachment on planetary limits, are proving to be catastrophic 
to the continued proliferation of endless infinities, fueled as they are by misconceived notions of progress, and a toxic concoction of neo-classical economics and Romantic individualism.

This confrontation with boundedness is the connecting theme underscoring, expressing, and exemplifying such cultural shifts as: the rise of ecological understanding, the deepening of environmental consciousness, the potentially transformative insights of ecological economics, and expressions of pre-emptive mourning for a deteriorating future.

This tightening of habitable boundaries around the Earth (visually, socially, imaginatively, scientifically) is causing what I call an "implosion of sensibility" -- a slow replacement of the images, metaphors and ideals of the infinite self of the modern individual with a new (and also in many ways very old) ethos based on the images, metaphors, and ideals of a finite, bounded person, earthbound -- a person whose growth and personal development is intensive rather than extensive.

The sources and implications of this belated, but quickening turn -- or return -- to living according to such a finite and bounded ethos are sketched out in the rest of this paper.

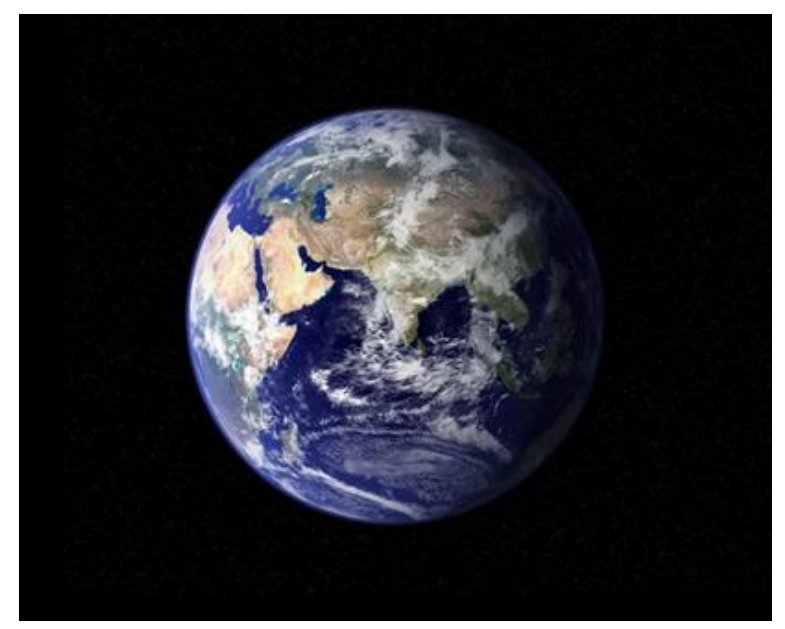

Figure 1. Planet Earth

\section{EXPLOSION AND AFTER}

In the 1970s, the prophetic theorist Marshall McLuhan argued that with the arrival of the image of the Earth from space, and with the almost simultaneous growth of the "satellite surround", there was no longer any wilderness left on earth (e.g. Culture is Our Business, 1970). More profoundly, and by making reference to the familiar image from Psychology textbooks of the figure/ground reversal (enshrined in the duck/rabbit or the kissers/flower vase (see Figure 2), McLuhan stated that the Earth, which was once the ground on which the human "figured", had now become a figure within the ground of the human enterprise. He noted that we are now able to hold the world in our heads and our hands. We can focus our attention on the world as a whole, and speak of "managing planet earth". It can become subject to global imperialism on a practical, local scale. We can drop drones on anyone we please anywhere we please. We have reached what was once the "God's eye view".
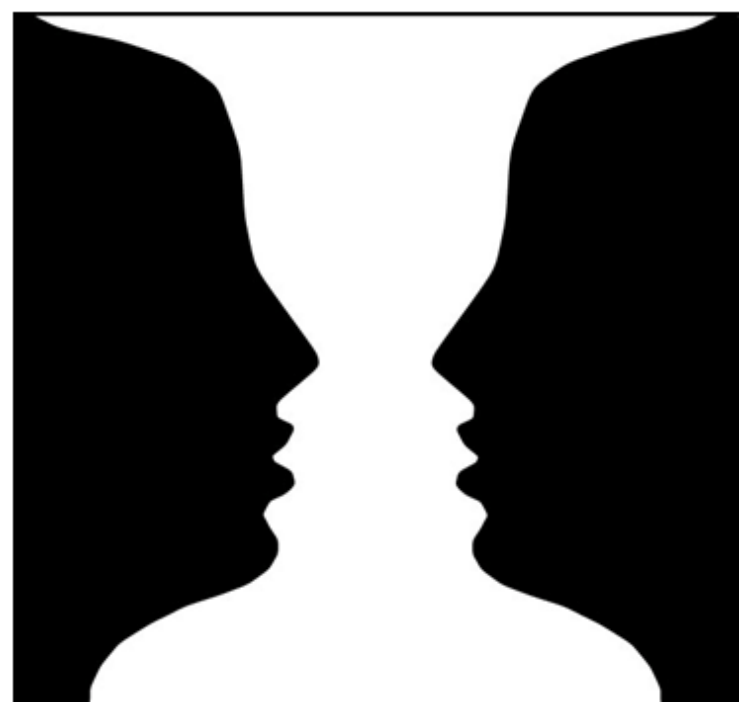

Figure 2.

Ironically enough, this encirclement of the earth, this revelation of its extraordinary living boundedness from a God's eye view perspective, was the unexpected result of a long dynamic drive towards the infinite -- what we 
might in fact call the modernist project of replacing God with ourselves. The aspirational agenda of modernity: freedom from constraint, freedom of movement, freedom from dependence on others, and of course immortality -- these derive from the original model, the omnipotent, omniscient, all-seeing God as a kind of draft, or "stalking horse" for us.

This modernist agenda was fueled by the wellknown sagas of the Scientific and Industrial Revolutions, those astonishing breakthroughs and breakings away from previous natural and technical constraints on population, agriculture and energy use; as well as the toppling of the ancient fossilized regimes of king and priest in the related sequence of political Revolutions (Wrigley, 2010) . This explosive dynamic of revolt from constraint was echoed and reinforced by a complementary dynamic creation and conceptualization of the modern individual, articulated most powerfully in the poetic stirrings of late 18th and 19th century Romanticism. While Romanticism itself came about in part as a resistance to the bleaker aspects of the emerging modern world, it ironically also contributed to the heroic glorification of the "strivings" of humankind to "break all the chains".

There is no room here to explore this topic in detail, except to say that Romantic individualism was born both as an internalization of the new powers of emerging modern heroes (cf. Napoleon), and as a reaction against the mobilization of mass numbers of people in industrial, military, and sociopolitical contexts (that is, I am not a statistic, I am an individual!). I simply cite a famous description of modern man released from bondage, as seen through the eyes of Percy Shelley:

The loathsome mask has fallen, the man remains

Sceptreless, free, uncircumscribed, but man Equal, unclassed, tribeless, and nationless, Exempt from awe, worship, degree, the king
Over himself; just, gentle, wise; but man

Passionless--no, yet free from guilt or pain,

Which were, for his will made or suffered them;

Nor yet exempt, though ruling them like slaves,

From chance, and death, and mutability,

The clogs of that which else might oversoar

The loftiest star of unascended heaven,

Pinnacled dim in the intense inane. (Prometheus Unbound, end of Act III (1820)

This is the Romantic individualist hope under construction. Human beings are not yet free of all constraints, but perhaps in time and with enough resources they will become as God, should they find a way around chance, and death, and change.

\section{INFINITE ECONOMICS}

This soaring desire was captured and reconfigured by the arrival of modern standard economics. Modern standard economics began as a description of the quickening movement of goods, services, and people in early capitalism, and then evolved from the middle of the 18th to the end of the 19th century into a strange quasiscientific model (dubbed neo-classicism) that sketched out the workings of an abstract market of utilitarian individuals rationally maximizing the fulfillment of their infinite desires under conditions of scarcity.

The appeal of this model to its originators, and to subsequent generations, is primarily due to its seeming explanatory power, its simplicity, purity, and its mathematizeability. It is one of the earliest systems models -- deliberately aping Newtonian physics -- and it contains within it an almost magical and paradoxical microlevel/macro-level opposition (deriving originally from Bernard de Mandeville's Fable of the Bees (1715), a satirical work that promoted spending on "private vice" as promoting employment and the enrichment of the larger "public virtue"). Thus, the individual pursuing personal aspirations, however self- 
interested, contributes unwittingly to the wellbeing of all. Adam Smith's Wealth of Nations (1776) carried this model further, and in more detail, and essentially founded modern economic theory. As a model, it captures some of the aspirations of the Romantic individual, marrying the expression of infinite aspiration to the emerging toolbox of 19th century physics and statistics. Ultimately, as economics developed, it produced the following rough little summary sketch: individuals have desires that are deemed to be essential to their selffulfillment; these desires can, on a grand scale, be managed and adjudicated through the neutral mechanism of market prices; everyone involved is assumed to have perfect information from which to make their choices; demand curves beautifully intersect supply curves; all markets clear; everything is either at, or tending towards equilbrium; etc., etc.

A further appeal of this model was that it also captured -- and subsequently fostered -- a modern phenomenon dubbed "disembedding". The basic idea of "disembedding", as originally described in the work of Karl Polanyi (The Great Transformation, 1944) and adopted by later influential sociologists like Anthony Giddens (1991), focusses on how the arrival of capitalism uprooted labour, land and capital from their original contexts and dissolved them into marketable commodities. Ripping people and things out of the web of their original homes and relationships enables them (to use Marxist terminology) to be priced according to "exchange value" as opposed to ordinary "use value", and thus makes them intercomparable and interchangeable with everything else. Once on the market, everything now has its price, and its value is that price. The specific, embedded character of things is replaced by whatever they are now worth, as priced in the universal market.

These forces of commodification and marketization are the acid bath of modernity as it spreads. Their assault on traditional webs of life has historically been the source of agonies of many kinds as they disembed, uproot and dissolve alternative forms of social and cultural meaning all over the world in the name of capitalist development. What has made this phenomenon particularly poisonous in the modern era is the combining of the dynamic of capitalist disembedding, fostered by neoclassical assumptions of theoretical purity, with the arrival of cheap fossil fuels.

Fossil fuels first generated the quintessential portable modern invention, the steam engine. These engines could be located almost anywhere (thus de-localizing energy supply). Then, as the Industrial Revolution proceeded, further inventions and applications of fossil fuels accelerated this process, particularly in transportation, to the point where we now live in what seems to be an energy-rich, frictionless landscape over which people, goods and services can locate and dislocate themselves at will, moving effortlessly, rootlessly, infinitely. California strawberries arrive at our tables year round practically for free (and have spawned the local food movement in counter- response). This is because cheap transportation has essentially flattened the world.

What is of course ignored in this delightful, seemingly almost cost-free global movement of people, goods and services is the massive, silent subsidy being paid for by the atmosphere -- to speak of only one affected sector of the biosphere -- and meanwhile greenhouse gas emissions multiply. This supposedly frictionless runawayness corrupts and unmoors everything from place, time, and even language, making it harder and harder to pin down what's going wrong, particularly with ourselves.

\section{IMPLOSION}

The end of this illusion of frictionless runawayness is now upon us. Climate change is the return of heat, that is, friction to our lives. The work of the Stockholm Resilience Centre headed by Johan Rockstr"om (first published in 2009, and updated in January 2015, has actually 
"earthed" the planetary boundaries concept -four of their proposed nine critical boundaries have now been crossed by humanity). The related concept of the "ecological footprint" has multiplied the non-existent extra planets we will need to keep the infinitizing bubble going. And so on. These are among the many convergent facts and concepts that, as stated earlier, have begun to generate the opposite of the exploding, centrifugal infinite. Like the mechanism and casing around an atomic bomb -- a timed series of conventional explosions that are driven inward to spark a critical nuclear mass -- the detonations of the ecological crisis are driving us inward, towards a re-valuation of our immanent dwelling place. We are witness to the arrival of a counter-force: a centripetal implosion of sensibility.

What this means, simply enough, is that we have moved into a period where many people are looking once more towards revaluing the worth of what it means to live on a finite world, our Earth -- the globe as locally focussed. Rather than seeking the infinite in some transcendent sphere, the immanent becomes the sacred realm. Some of this draws on what has long been a familiar spiritual path, as famously described by John Ruskin, Gerard Manley Hopkins, and William Blake: "To see a World in a grain of sand, and a Heaven in a wild flower."

What is striking about our time, so seemingly hell-bent on infinitism, is the way in which this emergent earthly concentration is, as it were, a major contributor to a the creation of what we could call a resistance force or movement against infinitism -- a movement increasingly widespread, most obviously connected to the rise of environmental consciousness. It is in some ways a resurgent homage to the call of the wonderments of the material world, given that we currently live in the least materialistic culture in history (since if we actually cared about material objects, we wouldn't treat them as nothing more than temporary carriers of dreams, to be tossed away when new dreams swim into view).

It has been noted in this context that once one draws a boundary around something, the internal parts of that thing become newly salient, visible, and interconnectedly sensitive. The economist Kenneth Boulding once put it this way: "The most worrying thing about (today's) earth is that there seems to be no way of preventing it from becoming one world. If there is only one world, then if anything goes wrong, then everything goes wrong." (Boulding, 1973). In recent history, this sensitivity began with the arrival of the nuclear age, through the prospect of the destruction within 15 minutes of everything we care about through the launching of intercontinental ballistic missiles triggered by conflicts far removed from our daily lives. This post-war global sensitivity was soon reinforced environmentally by the revelations of the insidious movement of distantly deposited chemicals percolating along the intricate web of global ecosystems, as most famously sketched out by Rachel Carson. And now, with each passing year, more of the elements of our global web become visible; light increasingly dawns over the planetary nervous system. We are plugged in, whether we like it or not, to the ultimate ecological coherence of our bounded world. The concept of the ecological web is the wiring diagram of the progress of the implosion, the internal expression of our natural boundedness.

As this implosion proceeds, we begin to rediscover the old ways of life of peoples who necessarily lived within natural boundaries, often within hard limits not of their own choosing. Their rules of life were hammered out by necessity. We find ourselves being drawn back, if not exactly to those previous necessities, yet to the world views that those necessities fostered. Peoples who lived according to the disciplines of nature once again speak to us with increasing resonance and relevance. They speak of what it means to cope 
and even thrive in a bounded world, a world of deep ecological embeddedness. Their hardearned wisdoms leap over modernity and postmodernity to re-emerge as urgently relevant to our new situation. There are multiple expressions of this re-emergence, from indigenous teachings to commitments to "slow living", to a resurrection of rituals of natural sacredness in religious traditions around the world. There are also cross-overs into aspects of contemporary biology, such as the immanent teleology of Hans Jonas and others (Jonas, 1966), and the new theories of auto-poeisis (Weber and Varela, 2002).

Most importantly, members of this emergent counter movement to infinitism find themselves drawn to a spirituality fostered by the implosion of sensibility, and find resonance in immanence, rather than transcendence. In the West, this means confronting the legacy of monotheistic thought and practice. The Western tradition still struggles with the legacy of a widespread belief, however crude theologically, in a transcendent and external God, a Creator separate from his creation, overseeing all, a God infinite, omnipotent, and unreachable. The so-called dynamic of the "death of God" over the last hundred or so years may have finished off that deity, but it nevertheless left the structure intact, like a haunted house emptied of its resident ghost. Western culture still mourns with God's loss the loss of its most powerful expression of transcendence, and still hearkens after it.

But perhaps our situation is prompting us to shake off that distant transcendence. Things as they are -- the ordinary -- are becoming born, or re-born into our wondering sight. In a finite world, we are drawn away from the obviously transcendent, at least in the form of the external Creator standing back from His creation like a Romantic artist surveying His masterpiece and seeing that it is good. In other traditions, such as Hinduism or Taoism or among the Hopi, the universe is an internal, self-organizing phenomenon. In certain of these traditions, externalist metaphors are replaced by metaphors such as the spider spinning its web from its own innards; or, more pointedly replacing male metaphors with female metaphors, such as the originary cosmic birth from a universal womb.

In learning to live in a finite world, we may find ourselves more drawn to the language of selforganization; to place rather than space; to intensive rather than extensive growth; to inscape not escape; to attitudes and practices we find in teachings such as the Stoic:

No longer let thy breathing just act in concert with the air which surrounds thee, but let thy intelligence also now be in harmony with the intelligence which embraces all things. For the intelligent power is no less diffused in all parts and pervades all things for him who embraces them, than in the life of the air we breathe.

(from Marcus Aurelius, Meditations, Book 8, 54)

In the Western tradition we can identify intimations of the resurgence of the finite sensibility in many ways; for example in the influence of classical Stoic traditions on contemporary environmentalism (as in the neoStoic philosophy of Spinoza's Ethics that underpins the Deep Ecology of Arne Naess).; or in the rediscovery of "green" aspects of Christianity.

From other traditions, as mentioned, such as Buddhism, there is an appeal to disciplines based on focussed insight into the interdependent basis of all things -- a movement inward to the contemplation of the selfless self. In the current fascination with Taoist thought and practice, one can find an aspiration towards developing a feeling for the rhythms of mutually defining energy that infuse the world. And again, from multiple indigenous traditions, there are resonant themes ranging from local ecological knowledge to sustainable lifeways that have endured for many centuries (I review 
a number of these in Brown and Timmerman, 2015).

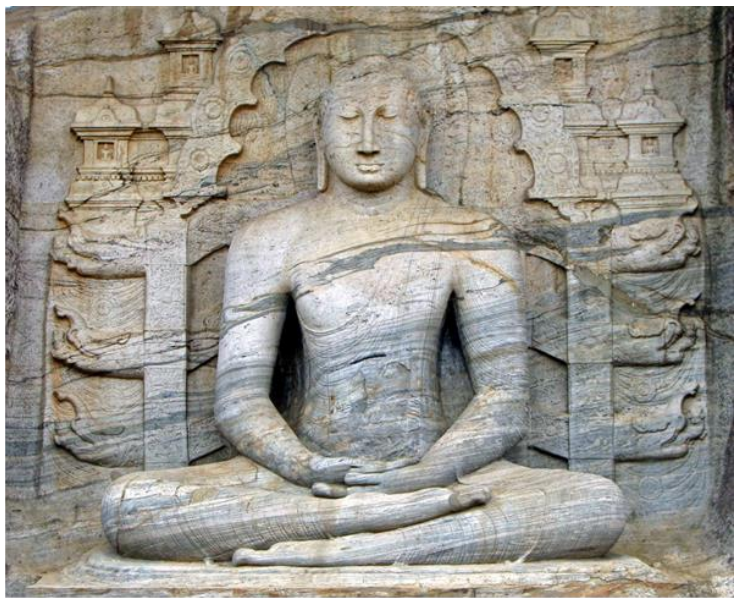

Figure 3.

In many of these traditions, the implosion of sensibility is paradoxically rooted in techniques for getting out of our egocentric way and letting insight from nature happen:

"Try to be mindful and let things take their natural course. Then your mind will become still in any surroundings, like a clear forest pool. All kinds of wonderful, rare animals will come to drink at the pool, and you will clearly see the nature of all things. You will see many strange and wonderful things come and go, but you will be still. This is the happiness of the Buddha."

-- Achaan Chah (1985)

Exploring all of the multiple aspects of this enriching implosion is far beyond the scope of this paper, but I want to focus on three aspects that I think have not yet received adequate attention, particularly in terms of my title -namely, how different "finitudes" can contribute to our learning to live in such a new (old) world; and then conclude with considerations of what the embracing of our boundary conditions means for the reembedding of language.

\subsection{FINITUDES I: CONDITIONS, NOT CONSTRAINTS}

First, we need to consider the notions of constraints and limits. I cannot find the reference, but I once read of a madman who asphyxiated himself because he was trying to find a substitute for breathing. As part of his madness, he was convinced that having to breathe every few seconds was a conspiracy to trap him in some complex web of deceit. This is a far cry from Marcus Aurelius's version of intelligent breathing, and is a pretty fair analogy to those who argue in favour of destroying the planet in the name of economic freedom.

A finite world view would among other things propose that true freedom involves a recognition (and an embracing) of our dependence on planetary processes -- that we are not victims of natural constraints, but beneficiaries of natural conditions. The physical and biological webs in which we are who we are, are not constraints on us, but the conditions of our existence. The bounds of the Earth are not a cage, but the source of whatever it is that we are: they are constitutive. Coming face to face with those conditions challenges us personally and socially in profound ways that we have hardly begun to fathom, and that terrify those I call "infinitists". For example, we are witnessing a current obsession with one-way travel to Mars, and a slate of contemporary movies about visiting planets multiple light years away. These are expressions of despair on the part of a culture grasping at the end of the infinite -- a culture turning away in fear from the prospect of being trapped here on a shrinking and degraded planet. It is a flight (literally) from the harder and deeper task of coming to a better self-understanding of what it means to be a creature of the Earth, earthy.

\subsection{FINITUDES II: ABUNDANCE, NOT SCARCITY}

Contrary to what would seem to be the obvious response to such concerns over the limits to the 
earth and the accumulating scarceness of resources to cope with a burgeoning population with ever increasing demands, one aspect of learning to live in our situation requires a reintroduction of a belief that the world is fundamentally abundant. This may sound demented, given the circumstances, but bear with it for a moment.

As mentioned already, modern neo-classical economics is predicated on the assumption of scarcity -- that there is not enough to go around, and that therefore we need to be in competition with each other, our competing desires requiring to be adjudicated in a market, etc., etc.

If one examines the ancient, classical and indigenous traditions of the world, the one assumption that is almost universally made is that the world is fundamentally abundant -- let us call this an ontology of primary abundance. We did not create the world, we do not keep it running, we do not provide the air, sun, water, fire, animals, plants, and the rest of the things around us, including us. These are essentially given to us. The prevalence of "gift relationships", however complicated they might become in these traditions, is grounded in some kind of homage to or replication of this foundational (and relational) gift of things. When scarcities do arise, they arise because the gods are angry; and they are usually angry because some human beings have sinned, made mistakes in the rituals invoking the gods, or otherwise strayed. There are endless examples of this, of which perhaps the best known are the hunting rituals among, for example, the Mistassini Cree of the James Bay region -- but replicated all over the world -- where the animals are the orchestrators of the hunt, and require obedience to very strict rules about how an animal is to be hunted and killed. If this obedience is ignored or transgressed, the animals withdraw their abundance (Berkes, 2012). This is an ontology of abundance based on mutual relationship, and assures an endless flow of sustainable life, if the wellsprings of that life are treated with respect and consideration.

In looking at alternative economic traditions around the world, one finds echoes of the same sentiments. In the West, we can refer to the precapitalist example of the spiritual economics of Francis of Assisi, based on the belief that God provides -- "Take no thought for the morrow" -and therefore one should throw oneself on the abundance of the Lord, and He will provide. Curiously enough, it worked spectacularly well for Francis, since historically the riches of Europe soon poured into his reluctant coffers.

Beginning in the early modern period in the West, a transition from an abundance ontology began to occur. Society began to shift in stages towards an ontology of primary scarcity and secondary abundance. It is ironic that with the arrival of the Industrial Revolution and the first taste of a moderate amount of wealth spreading through the general population, there began to develop a contrary dynamic of false, temporary scarcities associated with the emerging spending power of middle classes -- including the deliberate creation of fashion and the arrival of untethered commodity fetishism. It is at this point that early economic theoreticians (beginning with Bernard de Mandeville, David Hume, and Adam Smith) articulated powerful arguments that these false scarcities were in fact the primary condition of humanity: that in a world in which needs and desires were potentially infinite, scarcity was inevitable. This led to modern economics, as already described, and the full-scale adoption of our now familiar ontology of primary scarcity and secondary abundance. In a world of primary scarcity and secondary abundance there are no natural gifts. Nature will not -- cannot -- supply us on its own, it is recalcitrant, things hold themselves back -- we must work to "develop" the world. Our task is to create a secondary abundance to fill up the hole where the original abundance once was. 
The problem is that this artificial abundance can only mask the loss of the original abundance, and as a result we live in a society devoted to a dynamic of "development" that will not leave us be, a faith that grips the modern politician, planner, and citizen. Each new development and each new-and-improved product holds out the hope that it will assuage our primal loss, but in fact it merely reminds us of an emptiness in things. Advertising reinforces this by its seductive promise that something, someone, somewhere will one day satisfy our every desire, and upon the foundations of scarcity, we will build a new, and better abundance of our own making. Thus (as only one delusional example) we are asked to support massive economic growth in order to repair the ecological damage massive economic growth causes: digging a deeper hole as a way of filling in the hole we've already dug. And so, as our piling up of secondary abundance builds on an ontology of primary scarcity, we find ourselves ironically creating in the physical world actual, real, scarcities that are destroying the planet.

In contrast, a world of abundance knows nothing of limits. It knows about flourishing according to generous rules that are to be acknowledged and respected as the source of all the original gifts we have (and ourselves are). These rules emerge out of the primary, immanent abundance of things, and maintain them as long as we are prepared to obey them. It is a world of joy, of radiating being, of a generosity of giving rooted deep down things, and of learning to rejoice in a finite world.

\subsection{FINITUDES III: CYCLES, NOT LINES}

Essential to a world view committed to breaking limits is linearity -- we get into our cars, our most potent symbol of freedom, and after we hit the open road, we head for the frontier and smash through every border into the infinite beyond. This is just one of the fantasy gestures enshrined in contemporary music, television and movies. Modernity is all about abandoning the past in the name of progress and heading towards a beckoning, more fulfilling future. By contrast, moving inward, accepting boundaries, learning to live within our means seems like a failure of nerve. Yet, inexorably, with the increasing recognition of the necessary boundedness of the Earth, linearity reaches the end of the line --or it should, if catastrophe is to be averted.

And yet, what can progress be if not a civilizational attempt to move ever forward in a world that has lost any other transcendent purpose except progress, more and more and better and new? What are our lives if not a line that begins at birth and stops at death? Can there be anything more finite than that, awaiting us over the far horizon?

\section{But is the horizon a line?}

Towards the end of his life, Gregory Bateson, author of Steps to an Ecology of Mind (1968), began to wrestle with the status of the sacred in myth, story, and religious traditions. He never fully worked out the implications, but at one point he suggested that the ecological value of these traditions was as bearers of knowledge about larger cycles of implication. This knowledge was in fact ecological wisdom. In his writing about the role of the self in the struggle against alcoholism (Steps, p. 331) he remarked:

There is a Power greater than the self. Cybernetics would go somewhat further and recognise that the "self" as ordinarily understood is only a small part of a much larger trial-and-error system which does the thinking, acting, and deciding. This system includes all the informational pathways which are relevant at any given moment to any given decision. The "self" is a false reification of an improperly delimited part of this much larger field of interlocking processes.

Bateson saw that sacred traditions are like this: they beckon us to bigger systems and vaster 
circles, and that within those systems and circles we can find better resolutions to problems that seemed to be insurmountable when viewed from the tight circle of a "problem-solving" mindset. A similar critique is found in Wendell Berry's "Solving for Pattern" (1981) where, in discussing industrial farming, he states:

A bad solution is bad, then, because it acts destructively upon the larger patterns in which it is contained. It acts destructively upon those patterns, most likely, because it is formed in ignorance or disregard of them. A bad solution solves for a single purpose or goal, such as increased production. And it is typical of such solutions that they achieve stupendous increases in production at exorbitant biological and social costs.

Similarly, the Zen poet Gary Snyder once remarked:

"The biological-ecological sciences have been laying out (implicitly) a spiritual dimension. We must find our way to seeing the mineral cycles, the water cycles, air cycles, nutrient cycles as sacramental (Snyder, 1995)

From these insights, I take the idea that what we see as linearity is in fact only a series of segments or arcs of much larger circles or cycles, improperly delimited. Part of learning to live in a finite world is a committment to embeddedness in place or in relationship, and this in turn enables us to catch glimpses of the bending of the lines of our life horizon and engenders an intuitive feeling for the nesting of our life cycle within the larger eco- and geocycles. Our personal finitude becomes liberated when seen as part of a greater domain. I have sketched this out in a chart (see Figure 4). And, in addition, by becoming sensitive to the curvature of our lives, we enter into the arc of the long view of the Earth.

This connecting of the flow of things with our lives is, as mentioned earlier, essentially Taoist
-- the developing of a skill for feeling more deeply the contours of our Earthly embeddedness, and responding accordingly. This is reinforced by the teachings of Australian Aborigines concerning their song cycles. As recently stated by Galarrwuy Yunupingu, in a reflection on his life as leader of the Yolngu tribe:

"Our song cycles have the greatest importance in the lives of my people. They guide and inform our lives. A song cycle tells a person's life: it relates to the past, to the present and to the future. Yolngu balance our lives through the song cycles that are laid out on the ceremony grounds. These are the universities of our people, where we hone and perfect our knowledge. It is through the song cycles that we acknowledge our allegiance to the land, to our laws, to our life, to our ancestors and to each other. We work from the new moon to the full moon - travelling these song cycles as a guide to life and the essence of our people: keeping it all in balance so that wealth and prosperity might flow. This is the cycle of events that is in us and gives us the energy for life, the full energy that we require. Without this, we are nobody and we can achieve nothing."

(Yunupingu, 2016)

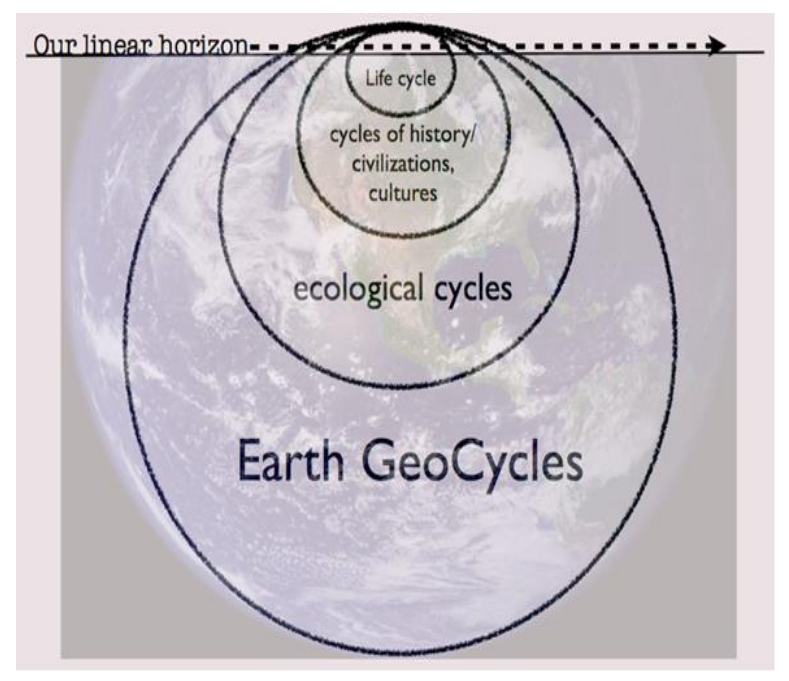

Figure 4. 


\section{CONCLUSIONS: CONDITIONS}

Our desire to escape the "limits" of the earth is like our desire to escape the limits of language. The philosopher Wittgenstein once pointed out that language is not a cage preventing us from getting past words to direct unmediated connection to the real world. Similarly, the physical and biological webs in which we are who we are, are not constraints on us but the conditions of our existence (see 5.1). By attempting to break out of the supposed cage of the Earth as presented to us, we threaten to enter a barren landscape without markers or meaning. Nothing grips, nothing holds in a frictionless world. "We have got on to slippery ice where there is no friction and so in a certain sense the conditions are ideal, but also, just because of that, we are unable to walk. Back to the rough ground!" (Philosophical Investigations, section 107).

Warnings of the danger of what I earlier referred to as the acid bath of modernity, or as "the frictionless", have a long history. In traditional societies there have been recurring theological and philosophical obsessions over such processes as "usury" and "interest". "Usury" -- charging extra for the return of borrowed funds, i.e. being parasitical on the "natural" uses of money -- was (in the Old Testament, the Koran, and elsewhere) considered to be a betrayal of alternative economic practices such as gift-giving, and more generally, was seen to be an undermining of personal relationships of lending and borrowing among community members and brethren. Sometimes obscurely, sometimes more clearly, theorists, theologians and citizens before the modern era worried that there was something about money and exchange that was troubling, over and above the potential for the obvious corruption of traditional ways of life. I suggest that among the sources of worry was a deep-rooted suspicion of the dematerialization of things -- that this dematerialization might lead to a runaway, rootless system operating without the brakes of materiality ("use value"), relationship, roots, or other forms of embedding that would keep such a system from expanding (thanks to illimitable desire) beyond appropriate, customary limits.

As a final concluding theme, I would suggest that if there is one overriding danger from uncontrolled infinitism, it could be the degradation of language -- that with the loss of solid grounding as expressed by Wittgenstein we can no longer speak to ourselves in meaningful terms about the urgency of the dangers we face. We find ourselves at a loss in trying to find the right words to argue, persuade, compel a world that outwardly proclaims its conversion to all things environmental, but continues to babble nonsensical mantras about unending economic growth and prosperity.

The best example of where this might lead, comes from Dostoyevsky's Crime and Punishment. In Crime and Puniishment, Dostoyevsky (who had an unparalleled sense of what was going wrong with the modern project) creates Raskolnikov, a young man who becomes a murderer and outcast because he believes that murder is a gesture of total freedom by "extraordinary men". By committing such an act Raskolnikov becomes instead a confused and lost soul, without bearings as he drifts vaguely through an opaque world, subject to the arbitrary gusts of his desires, feelings and emotions, and increasingly incoherent to himself and others. His freedom ends up as nothing but endless aimlessness. Only by admitting his guilt can he find himself again, and be reintegrated into, and through, common society and common decency. $\mathrm{He}$ recovers ordinary life and meaning, and can find peace.

In contrast to the degradation of language characteristic of a disembedded culture, an argument can be made that a re-embedding of language could potentially be the great outcome of this pivotal moment in human history, enabling us to learn (or re-learn) what it means 
to be who we are. Bateson's suggestion that we inhabit greater circles than we know can be supplemented by the insights of Michael Polanyi and the later Wittgenstein.

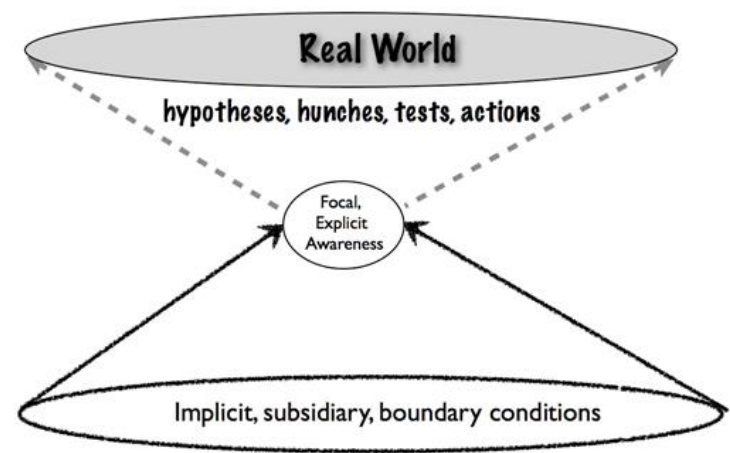

Figure 5.

In his classic work, Personal Knowledge (1958), Polanyi lays out the paradoxes of what he calls "latent or tacit knowledge" -knowledge that is required for "focal skills" (ranging from putting on our shoes to speaking English) but knowledge that isn't available to us in the tight circle of our focus, simply because it is what focuses the focus to its focal point(s). As first year philosophy students learn, we cannot step outside of seeing the world to judge whether our seeing of that world is accurate. Polanyi also refers to these forms of tacit or foundational knowledge as "implicit", "subsidiary" and "boundary conditions". We are unable to get to these forms to critique them, since they are what makes critique viable in the first place. Furthermore, when we do try to bring them "up into the light", they end up withering in the process of deliberate articulation. Yet in some sense the attempt to bring them up into articulation is what much of philosophy and certainly much of psychology is about (see Figure 5), not to mention the creative arts.

Wittgenstein explores a similar vein of attempting to "grasp the hand that grasps" in his last work, On Certainty (1972), but his variation on this theme comes much closer to the concerns of this paper. On Certainty is an extended argument against the possibility of total scepticism (a philosophical worry ever since at least Descartes), in part because:

"The questions that we raise and our doubts depend on the fact that some propositions are exempt from doubt, are as it were hinges on which those turn.... That is to say, it belongs to the logic of our scientific investigations that certain things are indeed not doubted....If I want the door to turn, the hinges must stay put." (\#341-344)

This line of argument is complementary to Wittgenstein's main philosophical task in his later work, namely showing that the actual logic of our use of language is embedded in what he calls "human natural history" or "forms of life", rather than in some abstract Platonic realm. Our linguistic practices depend on basic assumptions, assumptions so basic that articulating them seems to be banal and trivially obvious, e.g. that everyone has parents, that I have two hands, that I am subject to gravity (cited from McGinn (1989).

These basic working assumptions are what I would by extension call, borrowing from Polanyi, part of the constitutive or boundary conditions of life ; and among these conditions - as I have already stated a number of times in a variety of ways -- are the ecological conditions that constitute us as us. Wittgenstein links his version of these constitutive conditions to a range of subsequently useable concepts and images. Interestingly enough, one of his core examples is the image of the Earth from space with which I began this paper. He goes on:

"We form the picture of the earth as a ball floating free in space and not altering essentially in a hundred years. I said, 'We form the picture, etc.' and this picture now helps us in the judgement of various situations. (\#146)

"The picture of the earth as a ball is a good picture, it proves itself everywhere, it is also 
a simple picture -- in short we work with it without doubting it. (\#147)

The existence of the earth is rather part of the whole picture which is the starting point of belief for me. (\#209)

It is always by favour of Nature that one knows something (\#505).

For Wittgenstein, the picture of the Earth is, as it were, an ordering device operating helpfully midway between the tacit and the explicit. For us, it is more than that, it is an emergent and transformative frame, reconfiguring what belongs inside it, with the consequences I have been outlining in this paper.

For Wittgenstein (and Polanyi, in his own way):

"When we begin to believe anything, what we believe is not a single proposition, it is a whole system of propositions (Light dawns gradually over the whole) (\#141).

Similarly, I would argue that we grow up in a world whose boundary conditions encompass and define us, and that are now under pressure revealing to us the role the whole ecological realm of which we are a part plays in our selfconstitution. The sudden onset of awareness of our finitude -- the implosion of sensibility -brings these conditions up some distance (though not all the way) to our focal awareness. The Earth and our place in it comes into a more explicit, though not absolutely sharp view, since of course the natural world -- our natural world -- remains hopelessly complex. We are also faced with the horrible rips and tears and desecrations we have made to the original fabric of things, vandalisms that are forcibly interfering with our ability to re-stitch ourselves into Nature's weave. Still, to alter the metaphor, we can find in emerging concepts such as ecological economics, and in practical processes such as restoration ecology, deep urges to reconnect the downed wires of the Earth's webs of eco-communication. For environmentalists, one key role is to make as explicit as possible our implicit boundary conditions in order to to magnify -- or even simply bring into awareness -- their role in the realms of social and political judgement.

Ironically enough then, the crisis we are in provides us with the opportunity to learn more deeply what it is to be alive in this astonishingly beautiful, complex world. We may thus become clearer about what it is to be embedded hereabouts. And perhaps this emerging awareness is coming upon us just in time, at the moment when, as global forces relentlessly promote a misguided desire for a better somewhere else, we live on the verge of throwing away the only place that can ever truly teach us what it means to be creatures of the Earth.

\section{ACKNOWLEDGEMENT}

A first version of this paper formed the basis for a Keynote Address at the 19th International Symposium on Forestry and Environment, Sigirya, Sri Lanka, October 2014, organized by the University of Sri Jayewardenepura. Special thanks go to Prof. Hemanthi Ranasinghe and her colleagues for their thoughtful hospitality and assistance throughout my visit, and afterwards. Subsequent versions of this paper have been presented to the Canadian Club of Rome, the European SPES (Spirituality, Economics, and Society) Institute, and the Canadian Society for Ecological Economics. An abridged version has appeared in the magazine Alternatives. Support for travel grants from York University and the Faculty of Environmental Studies is gratefully appreciated.

\section{REFERENCES}

ARENDT H. The Human Condition. Chicago, Ill.: University of Chicago Press. 1998.

AURELIUS M. Meditations (trans. A.S.L. Farquharson). Oxford: Oxford World's Classics. 2008. 
BATESON G. Steps to an Ecology of Mind. Chicago, Ill: University of Chicago Press. [1968] 2000.

BERKES F. Sacred Ecology. New York, NY: Routledge. 2012. (3rd ed.).

BERRY W. "Solving for Pattern", Chapter 9 in The Gift of Good Land: Further Essays Cultural \& Agricultural . New York, NY: North Point Press. Originally published in the Rodale Press periodical The New Farm. 1981.

BIRD-DAVID N. "The Giving Environment: Another Perspective on the Economic System of Gatherer-Hunters". Current Anthropology, 1990. 31(2), 189-196. doi: 10.2307/2743592

BOULDING, K.E. "Spaceship Earth Revisited" in Economics, Ecology, Ethics: Essays Toward a Steady-State Economy, ed. H.E. Daly. New York, NY: W.H. Freeman: [1973] 1980. pp. 264-266.

BROWN PG \& P TIMMERMAN (eds.). Ecological Economics for the Anthropocene. New York, NY: Columbia University Press. 2015.

CHAH A.. A Still Forest Pool: The Insight Meditation of Achaan Chah, J. Kornfield and p. Breiter (eds). Wheaton, Ill.: Quest Books/The Theosophical Publishing House. 1985.

DOSTOYESKY F. Crime and Punishment (Pevear, R. and L. Volkonsky, trans.). New York, NY: Alfred A. Knopf. 1992.

FEYERABEND P. Conquest of Abundance: A Tale of Abstraction versus the Richness of Being. Chicago, Ill: University of Chicago Press. 1999.

FRANCIS OF ASSISI. Early Documents, Vol. 1 (W. J. Short, R. J. Armstrong \& J. A. W. Hellmann Eds. Vol. 1). New York: New City Press. 2002. 1205-1226.
FRIEDMAN M. "The Methodology of Positive Economics", Essays in Positive Economics. Chicago, Ill.: University of Chicago Press. 1953.

FRYE N. "Foreword", “The Drunken Boat: The Revolutionary Element in Romanticism", (and general editor), Romanticism Reconsidered: Selected Essays from the English Institute. New York, NY: Columbia University Press. 1963.

GIDDENS A. The Consequences of Modernity. Stanford, CA: Stanford University Press. 1990.

GUDEMAN S. Economics as Culture: Models and Metaphors of Livelihood. London; Boston, MA: Routledge \& Kegan Paul. 1986.

JONAS HANS. The Imperative of Responsibility. Chicago, Ill: University of Chicago Press. 1985.

LING TO. The Buddha: Buddhist Civilization in India and Ceylon. Harmondsworth, Middlesex: Penguin. 1976.

McGINN M. Sense and Certainty: A Dissolution of Scepticism. New York, NY: Blackwell. 1989.

McLUHAN M. Culture is Our Business. New York, NY: Ballantine Books. 1970.

On Certainty, G.E.M. Anscombe \& G.H. von Wright (eds). Oxford: Basil Blackwell. 1972.

POLANYI K. The Great Transformation. Boston, MA: Beacon Press. 1944.

POLANYI M. Personal Knowledge: Towards a Post-Critical Philosophy. Chicago, Ill.: University of Chicago Press. 1958.

ROCKSTRÖM J. et. al. "Planetary Boundaries: Exploring the Safe Operating Space for Humanity." Ecology and Society. 2009.14 (2): 32. 
http://www.ecologyandsociety.org/vol14/iss2/ar a32/.

RUSKIN J. "The Roots of Honour," from Unto This Last. In D. Birch (Ed.), Selected Writings (pp. 140-153). New York, NY: Oxford University Press. 2004 [1860].

SAHLINS M. Stone Age Economics. Chicago, Ill: Aldine-Atherton. 1972.

SHELLEY PB. Prometheus Unbound. 1820. https://andromeda.rutgers.edu/ jlynch/Texts/pro metheus.html [accessed August 2015].

SCHUMACHER EF. "Non-Violent Economics", The Observer. 1960. (August 21).

SCHUMACHER EF. Small is Beautiful: Economics as if People Mattered. New York, NY: Harper \& Row. 1973.

SNYDER G. A Place in Space: Ethics, Aesthetics, and Watersheds. Washington, D.C. Counterpoint. 1995.

SPINOZA B. Ethics, trans. E. Curley. Harmondsworth, Middlesex: Penguin Books.

Sutherland.S.1983. "The philosophical dimension:Self and freedom," in M.V. Jones and G.M.Terry (eds.), New Essays on Dostoyeysky. Cambridge: University Press. 1996.

TUCKER ME \& WILLIAMS DR. (Eds.). Buddhism and Ecology: The Interconnection of Dharma and Deeds. Cambridge, MA: Harvard University Press. 1997.

VICTOR PA. Managing without Growth: Slower by Design, Not Disaster. Cheltenham, UK: Edward Elgar. 2008.

WACKERNAGEL M. \& WE REES. Our Ecological Footprint: Reducing Human Impact on the Earth. Gabriola Island, BC: New Society Publishers. 1996.
WEBER A \& VARELA FJ. "Life after Kant: Natural purposes and the autopoietic foundations of biological individuality", Phenomenology and the Cognitive Sciences, I, 2002. 97-125.

WITTGENSTEIN L. Philosophical Investigations (3rd ed. trans. G.E.M. Anscombe). Oxford: Basil Blackwell. [1953] 1986.

WRIGLEY EA. Energy and the English Industrial Revolution. Cambridge, UK: Cambridge University Press. 2010.

YUNUPINGU G. "Rom Watangu", The Monthly. 2016. https://www.themonthly.com.au/issue/2016/july /1467295200/galarrwuy-yunupingu/romwatangu [Accessed, July 2016] 